\title{
Hybrid Au@alendronate nanoparticles as dual chemo-photothermal agent for combined cancer treatment
}

\author{
Anouchka Plan Sangnier ${ }^{1,2}$, Romain Aufaure ${ }^{1}$, Laurence Motte ${ }^{1}$, Claire Wilhelm ${ }^{*}, \ddagger 2$, \\ Erwann Guenin ${ }^{*} \neq 1,3$ and Yoann Lalatonne ${ }^{*} \neq 1,4$
}

\section{Letter}

\section{Address:}

${ }^{1}$ Inserm U1148, LVTS, Université Paris 13, Sorbonne Paris Cité, Bobigny, France, ${ }^{2}$ Laboratoire Matière et Systèmes Complexes, CNRS and University Paris Diderot, Paris, France, ${ }^{3}$ Sorbonne Universités, Université de Technologie de Compiègne, Integrated Transformations of Renewable Matter Laboratory (EA TIMR 4297 UTC-ESCOM), Compiègne, France and ${ }^{4}$ Service de Médecine Nucléaire, Hôpital Avicenne Assistance Publique-Hôpitaux de Paris, Bobigny, France

\section{Email:}

Claire Wilhelm* - claire.wilhelm@univ-paris-diderot.fr; Erwann Guenin * - erwann.guenin@utc.fr; Yoann Lalatonne* yoann.lalatonne@aphp.fr

* Corresponding author $\ddagger$ Equal contributors

\section{Keywords:}

alendronate; bisphosphonate; cancer treatment; gold nanoparticles; photothermia
Beilstein J. Nanotechnol. 2018, 9, 2947-2952.

doi:10.3762/bjnano.9.273

Received: 06 August 2018

Accepted: 26 October 2018

Published: 27 November 2018

This article is part of the thematic issue "Advanced hybrid nanomaterials".

Guest Editor: F. Leroux

(C) 2018 Plan Sangnier et al.; licensee Beilstein-Institut. License and terms: see end of document.

\begin{abstract}
A gold therapeutic nanoplatform with the same molecule used as reductant, coating and therapeutic agent has been developed in a one-pot, one-phase process using alendronate, a drug from the bisphosphonate family known for its antitumor effects. In addition, the core made of gold nanoparticles (NPs) brings thermal functionalities under irradiation within the first biological window (650-900 nm). The Au@alendronate nanoplatform thus provided a combined antitumor activity through drug delivery and photothermal therapy. Au@alendronate NPs inhibited in vitro the proliferation of prostate cancer cells (PC3) in a dose-dependent manner, with an $\mathrm{IC}_{50}$ value of $100 \mu \mathrm{M}$. Under NIR irradiation a temperature increase was observed leading to a reduction of the $\mathrm{IC}_{50}$ value to $1 \mu \mathrm{M}$, with total tumor cell death at $100 \mu \mathrm{M}$.
\end{abstract}

\section{Findings}

Bisphosphonates (BPs) are used in the treatment of a variety of bone diseases, such as osteoporosis, solid tumor bone metastases and myeloma bone disease [1-4]. BPs contain two phosphonate groups linked by a common carbon atom (P-C-P) binding divalent metal ions $\left(\mathrm{Ca}^{2+}, \mathrm{Mg}^{2+}\right.$, and $\left.\mathrm{Fe}^{2+}\right)$ by coordi- nation of the two phosphonate groups. The BP affinity for calcium is improved by adding a hydroxy $(-\mathrm{OH})$ group, for instance in HMBP (hydroxylmethylene bisphosphonate), allowing for a tridentate coordination to $\mathrm{Ca}^{2+}$ ions (Supporting Information File 1, Figure S4) and leading to a high affinity to 
bone (hydroxyapatite $\left.\left(\mathrm{Ca}_{10}\left(\mathrm{PO}_{4}\right)_{6}(\mathrm{OH})_{2}\right)\right)$ tissue [5,6]. We focus here on the antitumor activity of alendronate, a nitrogencontaining HMBP, clinically used as adjuvant $\left(\right.$ Fosamax $\left.{ }^{\circledR}\right)$ in the treatment of prostate and breast metastatic cancers [7]. Nitrogen-containing HMBPs, such as alendronate, are inhibitors of the mevalonate pathway. They inhibit the prenylation of GTPase proteins, which affects cell morphology, replication and signalling that can cause cell death by apoptosis $[8,9]$. However, the in vivo therapeutic use of HMBPs is limited by low bioavailability. Once intravenously injected, free HMBPs are only slightly internalized by the cells and accumulates preferentially into bone tissue. Benyettou et al. showed that alendronate-coated magnetic NPs favour the intratumoral uptake and inhibit tumor growth [10].

HMBPs are also effective ligands to stabilize nanoparticles under biological conditions [11-15]. More recently, synthesis of gold and silver NPs have been developed using HMPB molecules [16-18]. For gold NPs, HMBPs act as both Au chelating and reducing agent comparable to citrates in the well-known Turkevich-Frens synthesis [19,20]. Besides, gold NPs exhibit a unique surface plasmonic resonance leading to strong enhancement of the absorption and scattering when exposed to electromagnetic radiation [21]. Due to this plasmonic absorption, light is converted to heat [22-26]. Photothermal therapy (PTT) is a powerful cancer-treatment technique. Gold NPs have to be activated within the biological transparency windows of $650-950 \mathrm{~nm}$ or $1000-1350 \mathrm{~nm}$, to minimize light absorption by surrounding biological tissues [27]. The principal limitation of PTT is that it requires direct light irradiation, which reduces its effect against disseminated metastatic tumors. A promising strategy to increase the PTT efficiency is the combination with magnetic hyperthermia [28], or with chemotherapy [29,30].

Using a one-pot synthesis strategy, we developed Au@alendronate NPs for a combined application of the antitumor activity of alendronate and an efficient gold-mediated PTT. We further evaluated their combined chemo-photothermal antitumor activity.

\section{Synthesis and characterization of Au@alendronate NPs}

Gold NPs were synthesized in water by using alendronate both as reducing agent and chelating ligand. The gold solution is simply added to an alendronate solution at boiling temperature (see Supporting Information File 1). The excess of reactive species is eliminated by ultrafiltration. We thus obtained spherical NPs (Figure 1a, left) with an average diameter of a

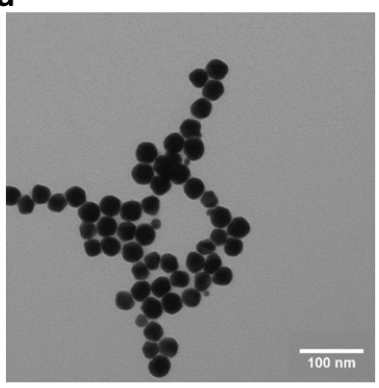

C

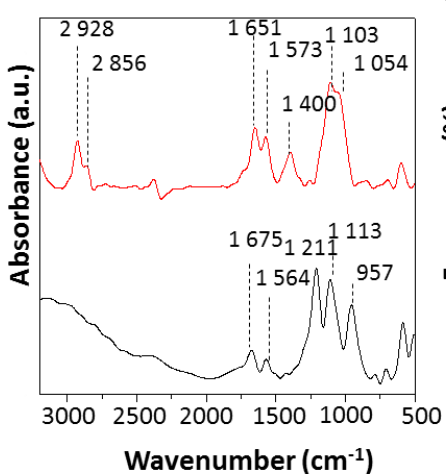

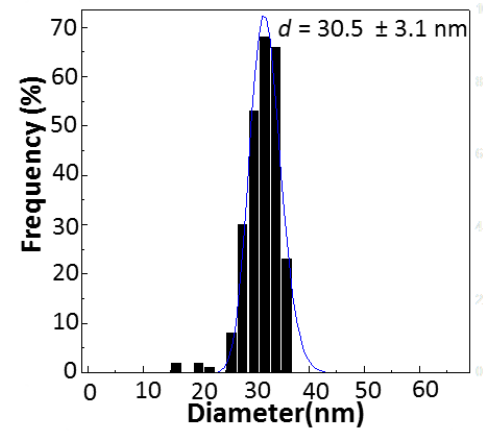

d

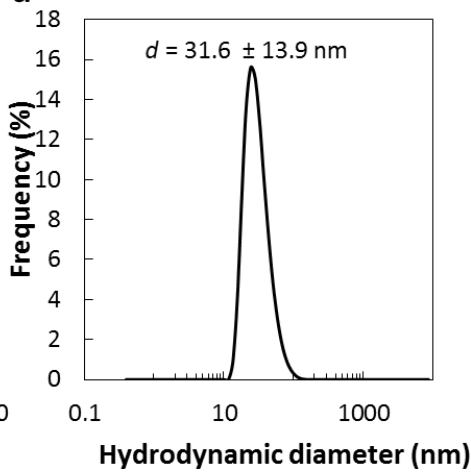

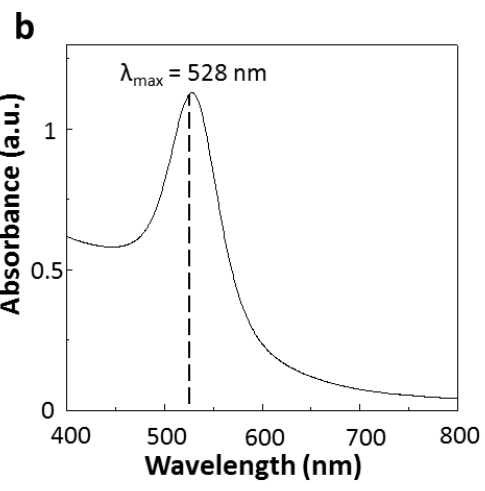

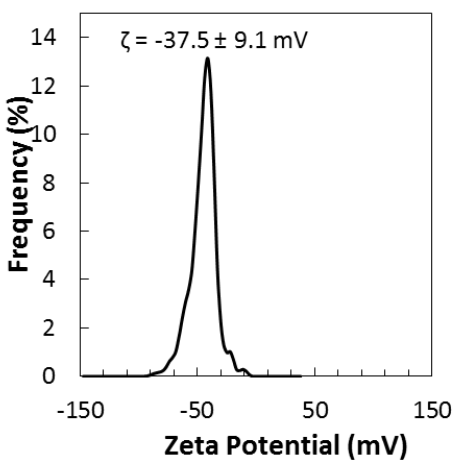

Figure 1: Au@alendronate NPs characterization: (a) transmission electron microscopy (TEM) image (left) and size distribution (right), (b) UV-vis spectrum, (c) FTIR spectra of Au@alendronate NPs (red curve) versus alendronate (black) curve, (d) Hydrodynamic diameter distribution (in volume, left) and zeta potential (right) of Au@alendronate NPs. 
$30.5 \pm 3.0 \mathrm{~nm}$ (Figure 1a, right) and a plasmon band at $528 \mathrm{~nm}$ (Figure 1b).

Under similar synthesis conditions, gold NPs obtained with (1-hydroxy-1-phosphonopent-4-enyl)phosphonic acid (HMBPene), replacing alendronate were characterized by a smaller NPs size around $10 \mathrm{~nm}$ [16]. This indicates the influence of the reducing ligand on the crystal growth. Inductively coupled plasma atomic emission spectroscopy (ICP-AES) has been used to quantitatively determine the amount of alendronate per nanoparticles. 1.0 $\mathrm{P}$ atoms per 7.6 Au atoms was measured, which corresponds to 36,427 alendronate molecules per NP or a coating density of 12.5 alendronate molecules $/ \mathrm{nm}^{2}$ for a $30.5 \mathrm{~nm}$ spherical gold NP. Remarkably, the alendronate density is much higher than estimated values for other NPs coated with HMBP molecules (i.e., 3.4 HMBPene $/ \mathrm{nm}^{2}$ ) [18]. Indeed, alendronate is a zwitterion, capable of forming pairs of ions that generate multilayers around the gold NP.

The chemisorption of alendronate was qualitatively assessed (Figure 1c) by Fourier-transform infrared spectroscopy (FTIR) comparing the coated gold NPs (red curve) with free alendronate (black curve). Large modifications were observed within the PO region $\left(900-1200 \mathrm{~cm}^{-1}\right)$. The free alendronate spectrum exhibits two sharp peaks at 1211 and $957 \mathrm{~cm}^{-1}$, assigned to $\mathrm{P}=\mathrm{O}$ and $\mathrm{P}-\mathrm{OH}$, respectively [31]. The broad band at $1113 \mathrm{~cm}^{-1}$ is characteristic for the vibrational mode for the $\mathrm{PO}_{3}$ group [32]. For $\mathrm{Au} @$ alendronate NPs the strong tightening of $\mathrm{P}=\mathrm{O}$ and $\mathrm{P}-\mathrm{O}$ vibration bands around $1000 \mathrm{~cm}^{-1}$ (red curve), which is characteristic of the chelation of phosphorus species on a metallic surface $[11,16,33]$, suggests a coordination of phosphonates as chelating groups. The $-\mathrm{NH}$ scissoring $\left(1564 \mathrm{~cm}^{-1}\right)$ and bending vibration bands $\left(1675 \mathrm{~cm}^{-1}\right)$ for alen- dronate were slightly shifted in the Au@alendronate NPs confirming the multilayer formation through anion/cation interactions due to the alendronate zwitterion form. These results suggest that alendronate was grafted onto the nanocrystal surface through the phosphonate groups and could be activated for further biocoupling [10].

The excellent coating density led to a good colloidal stability, as confirmed by dynamic light scattering (DLS) measurements at physiological $\mathrm{pH}$ values. A hydrodynamic diameter equal to $31.5 \pm 13.9 \mathrm{~nm}$ (Figure 1d) was determined, which is sufficiently close to the TEM crystal size to testify to the absence of gold NP aggregates. Au@alendronate NPs were stable at $\mathrm{pH}>4.7$ and at least four months after synthesis (see Supporting Information File 1, Figure S1). The negative zeta potential, equal to $-37.5 \pm 9.1 \mathrm{mV}$ confirms the presence of alendronate on the surface providing negative charges, which allow colloid stabilization despite the presence of ammonium cations.

\section{Au@alendronate NPs as NIR photothermal nano-heater}

Since gold NPs bring their own therapeutic asset, in the form of PTT, we first evaluated the specific photothermal properties of $\mathrm{Au} @$ alendronate NPs. In cancer therapy, it is desirable to use NPs that are active in the near-infrared (NIR) region to minimize light absorption of the laser radiation by surrounding tissues [27,34]. The plasmonic absorption band of Au@alendronate NPs is centered at $528 \mathrm{~nm}$, but there is still absorption above $800 \mathrm{~nm}$ (Figure 1b). Here, a laser operating at $680 \mathrm{~nm}$ and $0.3 \mathrm{~W} / \mathrm{cm}^{2}$ (Supporting Information File 1, Figure S2) and $1.7 \mathrm{~W} / \mathrm{cm}^{2}$ (Figure 2) was used. As we recently reported, this $1.7 \mathrm{~W} / \mathrm{cm}^{2}$ laser power was efficient for inducing tumor growth a

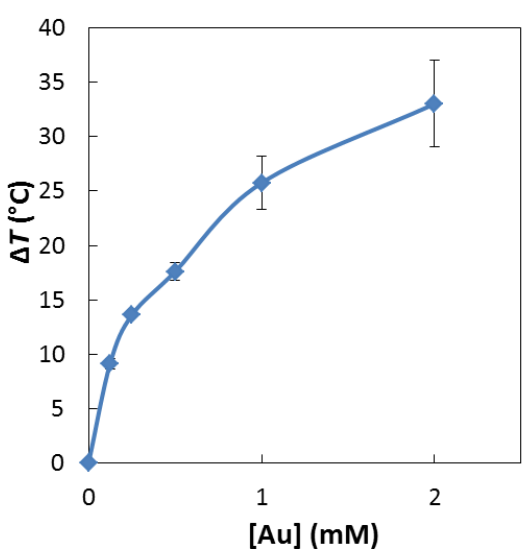

\section{b}

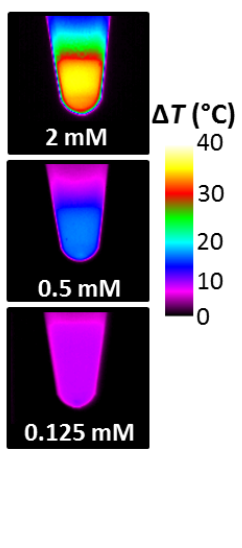

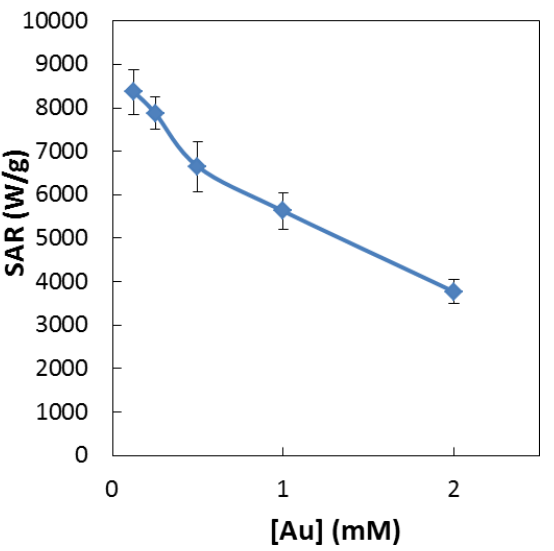

Figure 2: (a) Temperature increase and corresponding typical IR image and (b) SAR (W/g) as a function of the gold concentration under laser irradiation $\left(1.7 \mathrm{~W} / \mathrm{cm}^{2}, 680 \mathrm{~nm}\right)$. 
inhibition in vivo without exhibit nonspecific phototoxicity [35]. In addition, this value is lower than the power used in many in vivo studies [36-38]. Figure 2 summarizes the heating characteristics of Au@alendronate NPs, measured in water as a function of the gold concentration. Figure 2 shows the plateau temperatures reached after $5 \mathrm{~min}$ of irradiation (Figure $2 \mathrm{a}$ ), as well as the concentration-normalized heating efficiency expressed as the specific absorption rate (SAR) in watts per gram of $\mathrm{Au}$ (Figure 2b, see also Supporting Information File 1 for calculation details and Figure $\mathrm{S} 2$ for the temperature elevation at $0.3 \mathrm{~W} / \mathrm{cm}^{2}$ ).

The temperature elevation clearly increased with the gold concentration and reached $\Delta T=30^{\circ} \mathrm{C}$ at a gold concentration of $2 \mathrm{mM}$. A temperature increase of $\Delta T=9^{\circ} \mathrm{C}$ is observed at a low gold concentration of $0.125 \mathrm{mM}$. The SAR is above $4000 \mathrm{~W} / \mathrm{g}$ at high concentrations, reaching very high values (over $8000 \mathrm{~W} / \mathrm{g}$ ) at low concentrations. These photothermal properties are in good agreement with those of other thermal agents [23] and show the applicability of $\mathrm{Au@alendronate} \mathrm{gold}$ NPs as potential photothermal agents.

The colloidal stability of Au@alendronate NPs at physiological $\mathrm{pH}$ values and their photothermal properties within the NIR first biological window allowed us to further consider their study in a biological environment.

\section{Au@alendronate NPs antitumor activity}

PC3 human prostate adenocarcinoma cells were selected to explore the potential of Au@alendronate NPs as antitumor agents [9]. PC3 cells were first treated both with free alendronate and with Au@alendronate NPs (at various extracellular alendronate concentrations from $1 \mathrm{nM}$ up to $0.1 \mathrm{M}$ ) for $48 \mathrm{~h}$.
Metabolic activity (Figure 3) was determined by Alamar Blue assay (see Supporting Information File 1). With this assay the half maximal inhibitory concentration ( $\mathrm{IC}_{50}$ value) can be determined. This value is a good indicator of the effectiveness of a compound for inhibiting biological or biochemical functions. Free alendronate and Au@alendronate gold NPs reduced cell viability in a concentration-dependent manner (Figure 3a) with an $\mathrm{IC}_{50}$ equal to $100 \mu \mathrm{M}$ for both systems whereas Au@HMBP-PEG NPs [39] do not exhibit any cytotoxicity (Supporting Information File 1, Figure S3). Under similar celltreatment conditions, this $\mathrm{IC}_{50}$ value is consistent with values obtained for free alendronate with other cancer cell lines [10]. More importantly, it indicates that Au@alendronate NPs perfectly retained the antitumor activity of alendronate suggesting the alendronate release within the intracellular environment. However, at relevant concentrations, complete cell death was not achieved. Hence, we included photothermal treatment by using a $680 \mathrm{~nm}$ laser calibrated to illuminate cells at $1.7 \mathrm{~W} / \mathrm{cm}^{2}$. The metabolic activity on PC3 cells incubated with $\mathrm{Au} @$ alendronate NPs in presence or absence of laser irradiation is compared in Figure $3 b$.

At extracellular concentrations of alendronate below $1 \mu \mathrm{M}$, similar cell viability was observed in absence or presence of laser irradiation. This could be related to the low dose of internalized gold NPs and indicates that the laser power is sufficiently low to avoid nonspecific biological damage. At extracellular concentrations of alendronate over $1 \mu \mathrm{M}$, cell viability was considerably lowered in the presence of laser irradiation. $\mathrm{The}^{\mathrm{IC}_{50}}$ was reduced to $1 \mu \mathrm{M}$ (instead of $100 \mu \mathrm{M})$, while at intermediate concentration of $100 \mu \mathrm{M}$, cell death was total. It clearly evidences the efficiency of the combined drug delivery and photothermal treatment of Au@alendronate NPs.
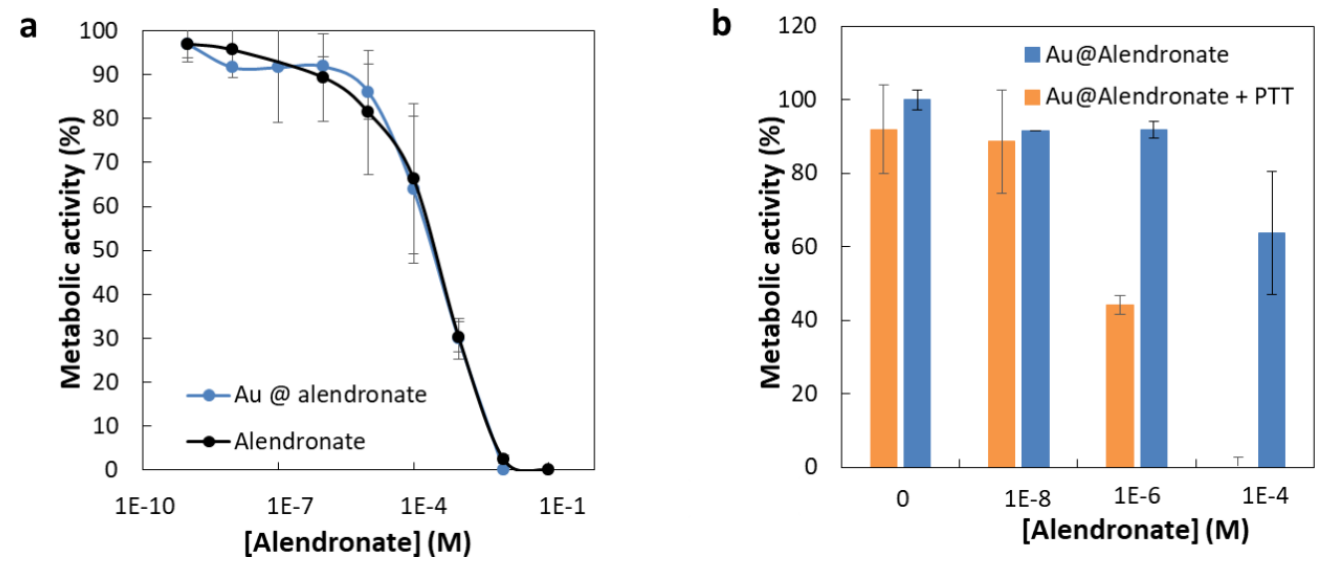

Figure 3: Metabolic activity of PC3 cells incubated (a) with free alendronate (black curve) and Au@alendronate NPs (blue curve), (b) with Au@alendronate NPs under the presence (orange column) or absence (blue column) of NIR irradiation (680 $\mathrm{nm}$ ). 
In summary, we developed a one-pot synthesis by simply mixing, in water, gold ions and alendronate molecules as reductant, coating and therapeutic agent. The synthesized Au@alendronate NPs maintain the alendronate antitumor activity, which is greatly improved under NIR laser radiation. These results pave the way for an efficient antitumor activity of $\mathrm{Au} @$ alendronate NPs through combining drug delivery in the form of a nanoplatform carrying alendronate and photothermal therapy. Indeed, Au@alendronate NPs will accumulate within cells because of the enhanced permeability retention effect: An enhanced permeability of blood vessels near the tumor allows for the penetration of nanoparticles into the tumor. The impaired lymphatic function within the tumor will not be able to clear those nanoparticles efficiently [40]. This proof-of-concept study will be completed by the intracellular behavior of Au@alendronate NPs with a special attention to alendronate release under photothermal activation.

\section{Supporting Information}

\section{Supporting Information File 1}

Materials and methods and supplementary figures.

[https://www.beilstein-journals.org/bjnano/content/ supplementary/2190-4286-9-273-S1.pdf]

\section{Acknowledgements}

We thank the CNanoMat platform (University Paris 13) for physico-chemical characterization. We acknowledge financial support from Sorbonne Paris Cité (project CardioNanoStem). We acknowledge the ImagoSeine facility (Jacques Monod Institute, Paris, France), and the France BioImaging infrastructure supported by the French National Research Agency (ANR-10INSB-04, «Investments fit the future». This research was also sponsored by the European Union, the Région Haut de France, the Ecole Supérieur de Chimie Organique et Minérale (ESCOM) and Université de Technologie de Compiègne (UTC) through FEDER funding of the chair: «Green Chemistry and Processes».

\section{$\mathrm{ORCID}^{\circledR}$ iDs}

Anouchka Plan Sangnier - https://orcid.org/0000-0002-4799-7149 Laurence Motte - https://orcid.org/0000-0001-6129-539X Claire Wilhelm - https://orcid.org/0000-0001-7024-9627 Erwann Guenin - https://orcid.org/0000-0002-7125-9074 Yoann Lalatonne - https://orcid.org/0000-0003-2235-6561

\section{References}

1. Eriksen, E. F.; Díez-Pérez, A.; Boonen, S. Bone 2014, 58, 126-135. doi:10.1016/j.bone.2013.09.023
2. Abdelkarim, M.; Guenin, E.; Sainte-Catherine, O.; Vintonenko, N.; Peyri, N.; Perret, G. Y.; Crepin, M.; Khatib, A.-M.; Lecouvey, M.; Di Benedetto, M. PLoS One 2009, 4, e4685. doi:10.1371/journal.pone.0004685

3. Macedo, F.; Ladeira, K.; Pinho, F.; Saraiva, N.; Bonito, N.; Pinto, L.; Gonçalves, F. Oncol. Rev. 2017, 11, 321. doi:10.4081/oncol.2017.321

4. Polascik, T. J. Drug Des., Dev. Ther. 2009, 3, 27-40. doi:10.2147/dddt.s3169

5. Nancollas, G. H.; Tang, R.; Phipps, R. J.; Henneman, Z.; Gulde, S.; Wu, W.; Mangood, A.; Russell, R. G. G.; Ebetino, F. H. Bone 2006, 38, 617-627. doi:10.1016/j.bone.2005.05.003

6. Russell, R. G. G. Bone 2007, 40, S21-S25. doi:10.1016/j.bone.2007.03.002

7. Mundy, G. R. Nat. Rev. Cancer 2002, 2, 584-593. doi:10.1038/nrc867

8. Luckman, S. P.; Hughes, D. E.; Coxon, F. P.; Russell, R. G. G.; Rogers, M. J. J. Bone Miner. Res. 1998, 13, 581-589. doi:10.1359/jbmr.1998.13.4.581

9. Virtanen, S. S.; Väänänen, H. K.; Härkönen, P. L.; Lakkakorpi, P. T. Cancer Res. 2002, 62, 2708-2714.

10. Benyettou, F.; Lalatonne, Y.; Chebbi, I.; Benedetto, M. D.; Serfaty, J.-M.; Lecouvey, M.; Motte, L. Phys. Chem. Chem. Phys. 2011, 13, 10020-10027. doi:10.1039/c0cp02034f

11. Lalatonne, Y.; Paris, C.; Serfaty, J. M.; Weinmann, P.; Lecouvey, M.; Motte, L. Chem. Commun. 2008, 2553-2555. doi:10.1039/b801911h

12. Giger, E. V.; Puigmartí-Luis, J.; Schlatter, R.; Castagner, B.; Dittrich, P. S.; Leroux, J.-C. J. Controlled Release 2011, 150, 87-93. doi:10.1016/j.jconrel.2010.11.012

13. Karimi, A.; Denizot, B.; Hindré, F.; Filmon, R.; Greneche, J.-M.; Laurent, S.; Daou, T. J.; Begin-Colin, S.; Le Jeune, J.-J. J. Nanopart. Res. 2010, 12, 1239-1248. doi:10.1007/s11051-009-9815-7

14. Torres Martin de Rosales, R.; Tavaré, R.; Paul, R. L.; Jauregui-Osoro, M.; Protti, A.; Glaria, A.; Varma, G.; Szanda, I.; Blower, P. J. Angew. Chem., Int. Ed. 2011, 50, 5509-5513. doi:10.1002/anie.201007894

15. Bolley, J.; Guenin, E.; Lievre, N.; Lecouvey, M.; Soussan, M.; Lalatonne, Y.; Motte, L. Langmuir 2013, 29, 14639-14647. doi:10.1021/la403245h

16. Aufaure, R.; Lalatonne, Y.; Lièvre, N.; Heintz, O.; Motte, L.; Guénin, E. RSC Adv. 2014, 4, 59315-59322. doi:10.1039/c4ra11847b

17. Benyettou, F.; Rezgui, R.; Ravaux, F.; Jaber, T.; Blumer, K.; Jouiad, M.; Motte, L.; Olsen, J.-C.; Platas-Iglesias, C.; Magzoub, M.; Trabolsi, A. J. Mater. Chem. B 2015, 3, 7237-7245. doi:10.1039/c5tb00994d

18. Aufaure, R.; Hardouin, J.; Millot, N.; Motte, L.; Lalatonne, Y.; Guénin, E. Chem. - Eur. J. 2016, 22, 16022-16027. doi:10.1002/chem.201602899

19. Turkevich, J.; Stevenson, P. C.; Hillier, J. Discuss. Faraday Soc. 1951, 11, 55-75. doi:10.1039/df9511100055

20. Frens, G. Nature (London), Phys. Sci. 1973, 241, 20-22. doi:10.1038/physci241020a0

21. Jain, P. K.; Lee, K. S.; El-Sayed, I. H.; El-Sayed, M. A. J. Phys. Chem. B 2006, 110, 7238-7248. doi:10.1021/jp057170o

22. Panikkanvalappil, S. R.; Hooshmand, N.; El-Sayed, M. A. Bioconjugate Chem. 2017, 28, 2452-2460. doi:10.1021/acs.bioconjchem.7b00427

23. Espinosa, A.; Kolosnjaj-Tabi, J.; Abou-Hassan, A.; Plan Sangnier, A.; Curcio, A.; Silva, A. K. A.; Di Corato, R.; Neveu, S.; Pellegrino, T.; Liz-Marzán, L. M.; Wilhelm, C. Adv. Funct. Mater. 2018, 28, 1803660. doi:10.1002/adfm.201803660 
24. Lohse, S. E.; Murphy, C. J. J. Am. Chem. Soc. 2012, 134, 15607-15620. doi:10.1021/ja307589n

25. Dykman, L.; Khlebtsov, N. Chem. Soc. Rev. 2012, 41, 2256-2282. doi:10.1039/c1cs15166e

26. Espinosa, A.; Silva, A. K. A.; Sánchez-Iglesias, A.; Grzelczak, M.; Péchoux, C.; Desboeufs, K.; Liz-Marzán, L. M.; Wilhelm, C. Adv. Healthcare Mater. 2016, 5, 1112. doi:10.1002/adhm.201670046

27. Tsai, M.-F.; Chang, S.-H. G.; Cheng, F.-Y.; Shanmugam, V.; Cheng, Y.-S.; Su, C.-H.; Yeh, C.-S. ACS Nano 2013, 7, 5330-5342. doi:10.1021/nn401187c

28. Espinosa, A.; Bugnet, M.; Radtke, G.; Neveu, S.; Botton, G. A.; Wilhelm, C.; Abou-Hassan, A. Nanoscale 2015, 7, 18872-18877. doi:10.1039/c5nr06168g

29. Nam, J.; Son, S.; Ochyl, L. J.; Kuai, R.; Schwendeman, A.; Moon, J. J. Nat. Commun. 2018, 9, 1074. doi:10.1038/s41467-018-03473-9

30. Li, Y.; Liu, G.; Ma, J.; Lin, J.; Lin, H.; Su, G.; Chen, D.; Ye, S.; Chen, X.; Zhu, X.; Hou, Z. J. Controlled Release 2017, 258, 95-107. doi:10.1016/j.jconrel.2017.05.011

31. Podstawka, E.; Borszowska, R.; Grabowska, M.; Drag, M.; Kafarski, P.; Proniewicz, L. M. Surf. Sci. 2005, 599, 207-220. doi:10.1016/j.susc.2005.09.048

32. Gao, W.; Dickinson, L.; Grozinger, C.; Morin, F. G.; Reven, L. Langmuir 1996, 12, 6429-6435. doi:10.1021/la9607621

33. Benyettou, F.; Guenin, E.; Lalatonne, Y.; Motte, L. Nanotechnology 2011, 22, 055102. doi:10.1088/0957-4484/22/5/055102

34. Weissleder, R. Nat. Biotechnol. 2001, 19, 316-317. doi:10.1038/86684

35. Plan Sangnier, A.; Preveral, S.; Curcio, A.; K. A. Silva, A.;

Lefèvre, C. T.; Pignol, D.; Lalatonne, Y.; Wilhelm, C.

J. Controlled Release 2018, 279, 271-281. doi:10.1016/j.jconrel.2018.04.036

36. von Maltzahn, G.; Park, J.-H.; Agrawal, A.; Bandaru, N. K.; Das, S. K.; Sailor, M. J.; Bhatia, S. N. Cancer Res. 2009, 69, 3892-3900. doi:10.1158/0008-5472.can-08-4242

37. Dickerson, E. B.; Dreaden, E. C.; Huang, X.; El-Sayed, I. H.; Chu, H.; Pushpanketh, S.; McDonald, J. F.; El-Sayed, M. A. Cancer Lett. 2008, 269, 57-66. doi:10.1016/j.canlet.2008.04.026

38. Zheng, X.; Zhou, F.; Wu, B.; Chen, W. R.; Xing, D. Mol. Pharmaceutics 2012, 9, 514-522. doi:10.1021/mp200526m

39. Aufaure, R.; Buendia, R.; Motte, L.; Hardouin, J.; Lalatonne, Y.; Guénin, E. New J. Chem. 2017, 41, 12153-12158. doi:10.1039/c7nj02773g

40. Greish, K. Enhanced Permeability and Retention (EPR) Effect for Anticancer Nanomedicine Drug Targeting. In Cancer Nanotechnology; Grobmyer, S. R.; Moudgil, B. M., Eds.; Methods in Molecular Biology; Humana Press: New York City, NY, U.S.A., 2010; pp 25-37. doi:10.1007/978-1-60761-609-2_3

\section{License and Terms}

This is an Open Access article under the terms of the Creative Commons Attribution License (http://creativecommons.org/licenses/by/4.0). Please note that the reuse, redistribution and reproduction in particular requires that the authors and source are credited.

The license is subject to the Beilstein Journal of Nanotechnology terms and conditions: (https://www.beilstein-journals.org/bjnano)

The definitive version of this article is the electronic one which can be found at:

doi:10.3762/bjnano.9.273 